\title{
Illuminating the seismicity pattern of the October 8, 2005, M=7.6 Kashmir earthquake aftershocks
}

\author{
Steven J. Gibbons and Tormod Kværna ${ }^{1}$ \\ NORSAR, Gunnar Randers vei 15, P.O. Box 53, 2027 Kjeller, Norway.
}

\begin{abstract}
Aftershocks of the October 8, 2005, M=7.6 Kashmir earthquake continued for many weeks and covered a region extending over an aperture exceeding 100 $\mathrm{km}$. Several hundred events were recorded well at teleseismic distances while many hundreds more are only observed at regional distances. Existing earthquake catalogs for this sequence are poor given an unfavorable distribution of stations, a complex tectonic setting, lack of local and near-regional data, and under-exploitation of the most sensitive stations. Advances in automated signal processing, improvements in seismic velocity models, and innovations in multiple event location algorithms have made it worthwhile revisiting this sequence and attempting a large-scale relocation of the aftershocks. A vast number of new phase readings have been made on permanent and temporary seismic stations both at regional and teleseismic distances and the Bayesian hierachical multiple event location program Bayesloc was employed in multiple stages, resulting in a far more structured distribution to the seismicity. The relocated aftershocks fall mainly into two distinct clusters. One cluster lies predominantly North East of the Balaklot-Bagh Thrust and South of the Main Central Thrust, with the October 8 main shock at its most northern point. The second cluster occupies the Indus-Kohistan Seismic Zone, North of the Main Central Thrust and South of the Main Mantle Thrust. Both clusters lie North East of a NW-SE trending boundary almost parallel to the southern part of the surface rupture. An East
\end{abstract}

\footnotetext{
${ }^{1}$ steven@norsar.no, tormod@norsar.no
}

Preprint submitted to Physics of the Earth and Planetary Interiors 
South East trending strand of earthquakes extends from the most northerly turning point of the Main Central Thrust into the Kashmir Basin, and a scattering of events are located North of this line and South of the Main Mantle Thrust. The new location estimates result in those aftershocks with the most similar focal mechanisms being far more spatially clustered than in previously published catalogs. Mapping global CMT solutions before and after the relocation contributes to the confidence in the new epicenters and provides a clearer picture of how the source parameters vary over the aftershock region. All files required to reproduce the results using the Bayesloc program are provided.

Keywords: Kashmir, earthquake, aftershocks, relocation

\section{Introduction}

घ The October 8, 2005, M=7.6 Muzaffarabad earthquake, Kashmir, (Bendick et al., 2006; Mandal et al., 2007, Pathier et al., 2006; Parsons et al., 2006. MonaLisa, 2009) was followed by thousands of aftershocks, many hundreds of

5 which were recorded at global distances. The duration and spatial extent of the aftershock sequence for this event was exceptional for earthquakes of comparaple magnitude in the India-Asia collision belt (Parsons et al. 2012, Tahir and Grasso, 2014) and improved aftershock location estimates could be significant in understanding the structure and tectonics of the region (e.g. Bilham, 2004, Ali

10 et al., 2009, Jouanne et al., 2011; Kaneda et al., 2008: Yan et al., 2013; Bungum et al. 2017). An accurate event catalog for the sequence is also necessary for an pvaluation of the properties of seismic waveforms across the region (e.g. Slinkard et al. 2013) and analyzing of models of source properties from the aftershock distribution (e.g. Lieshout and Stein, 2012, Türkyilmaz et al., 2013).

The existing seismic catalogs for the sequence have shortcomings resulting from a lack of data from nearby stations, an under-exploitation of existing data, and not taking advantage of the latest innovations in event location algorithms. The lack of local data of course cannot be rectified, but a careful reconsideration of the existing waveforms, improved global seismic velocity models, and contex- 
tual approaches to seismic event location may result in a far more plausible distribution of aftershock epicenters. Figure 1 displays the aftershock distributions taken from two different bulletins: the Reviewed Event Bulletin (REB) of the International Data Center for the Comprehensive Nuclear-Test-Ban Treaty (CTBT), and the International Seismological Center (ISC). The large-scale char25 acteristics of the two catalogs are the same with the aftershocks mainly divided into two large clusters: one to the South and South East of the main shock and one to the North West. Parsons et al. (2012) point out a likely causality of events in the two clusters from the M7.6 main shock (southern cluster) and an M6.4 aftershock (northern cluster). However, a closer inspection makes it clear that the uncertainty in the individual event location estimates means that fine-scale structure of the aftershock activity is not resolved.

In this paper we provide an overview of the seismic waveforms openly available to the scientific community, discuss the deficiencies of the existing seismic bulletins, and discuss how three factors in particular warrant a reanalysis of this sequence. Firstly is advances in signal processing. Extensive aftershock sequences provide enormous challenges for data centers compiling near-realtime bulletins and a large effort is being made to facilitate the automatic processing of such sequences, in particular using pattern detectors (e.g. Harris and Dodge, 2011, Gibbons et al. 2012, Dodge and Harris, 2016; Junek et al., 2015). We have

40 applied the multi-stage approach described by Gibbons et al. (2016) to both regional and teleseismic waveforms from the Kashmir sequence and performed an almost autonomous event detection and location procedure.

The second factor is an improvement in seismic velocity models used for event location. A progressive improvement in 1-D models for traveltime prediction 45 led to the AK135 model (Kennett et al. 1995) which, almost 20 years later, is still the workhorse for global event location. However, large events wellconstrained with teleseismic phases, with low time-residuals relative to AK135, often show high residuals for local and regional phases that have propagated through the more heterogeneous crust and uppermost mantle (very evident for the ISC catalog of the Kashmir events). It follows that the location estimates 
for smaller events, constrained only by regional phases, are likely to be biased if the inaccuracies in the velocity model are not accounted for. Efforts to mitigate this have evolved from correction terms for individual paths (e.g. Murphy et al. 2005), to regionalized models for traveltime calculation (Myers et al., 2010), 55 to global 3-dimensional models (Myers et al., 2015; Ballard et al., 2016). We now have at our disposal a 3-dimensional global P- and S-wave velocity model anticipated to improve significantly the representation of traveltimes in central Asia (Simmons et al. 2015).

The third factor is algorithms for event location. The classical earthquake location methodology finds a hypocenter and an origin time which minimizes the norm of a vector of residuals between model-predicted and observed traveltimes. Joint Epicentral Determination (Douglas, 1967) mitigated location inaccuracy due to regional bias when multiple events could be located simultaneously, since station traveltime corrections could be solved for. This idea is extended in the double-difference family of location methods (Waldhauser and Ellsworth, 2000) in which closely spaced events, in particular those with almost repeating signals, are located relative to each other with far greater accuracy than a single-event location procedure could achieve. The aftershock region for the Kashmir sequence is very large and Slinkard et al. (2013) demonstrated that waveform 70 similarity between events in this sequence was extremely limited, reducing the applicability of correlation-based relative event location procedures. The state of the art for locating extended clusters of seismic events is probably Bayesloc (Myers et al., 2007, 2009). This Bayesian hierarchical multiple seismic event locator estimates a joint probability distribution of event locations, corrections to traveltime predictions, and specifications of the arrival times. Bayesloc can be demonstrated to provide enhanced location estimates for clustered events, particularly for situations where prior probabilistic constraints can be applied to input parameters. Myers et al. (2011) demonstrate hypocenter relocations for events in the Middle East using Bayesloc with multiple events. The improvement relative to the catalog locations is significant given that the demonstrably incorrect implicit assumptions of zero mean and uncorrelated errors are treated 
realistically in the probabilistic location algorithm.

The relocations performed here are carried out using Bayesloc, with traveltime tables calculated using the most recent 3-dimensional $\mathrm{P}$ - and $\mathrm{S}$-wave velocity models for the region (details regarding access to the software and velocity models are provided in the acknowledgements section). An exceptional effort, using both automated and manual arrival picking, has been made to identify Pand S- arrivals from stations at regional distances, the majority of which have not been exploited in the existing event catalogs.

\section{Available seismic data}

Figure 2 shows the locations of seismic stations of the International Monitoring System (IMS) for monitoring compliance with the CTBT. Only the stations with black symbols were available for compiling the REB at the time of the Kashmir sequence (Figure 1 a). The stations with white symbols include those which simply didn't exist at the time (e.g. GEYT, USRK), those yet to be certified as IMS stations (e.g. KSRS, TORD), and those which were being serviced or upgraded (e.g. ASAR). The geographical distribution of the stations present is unfortunate for the quality of event locations with the most of the best stations for signal detection for Kashmir earthquakes located in Europe. The sensitivity of stations to signals generated by seismic events varies enormously (Kværna and Ringdal, 2013) with detection capability dependent both on local noise levels and on path characteristics (which often can only be determined empirically). In addition, array stations almost always perform better for signal detection and parameter estimation than 3-component stations. To the South is only a single seismic array (WRA) and coverage to the South West is limited to a few 3-component stations, of which only KMBO (Kenya) recorded a significant number of teleseismic P-arrivals.

The closest IMS array (MKAR: Makanchi in Kazakhstan) has a relatively poor detection performance for this particular sequence with emergent P-phases 
Kazakhstan) is somewhat further away but recorded far more signals with high signal-to-noise ratio (SNR). Unfortunately, for the compilation of the REB, BVAR is a so-called auxiliary IMS station and is not used for signal detection at the International Data Center (IDC). The Zalesovo array in Russia was also not built at the time of the Kashmir earthquake although the 3-component station ZAL was in operations. Other IMS arrays for which data is not available have almost co-located IRIS 3-component stations as possible surrogates (e.g. ABKT is almost co-located with GEYT and CHTO with CMAR).

Figure 3 shows the locations of open seismic stations at regional and farregional distances to the Kashmir sequence. Most of these are non-IMS stations and phase readings from many of the stations are used in the event locations displayed in Figure 1 b). The closest station by far (with openly available data) is NIL - Nilore, Pakistan - although readings from this station were not used for any of the event locations displayed. The signals at NIL for the largest events are clipped but the first $\mathrm{P}$ arrival is almost always discernible and clear $\mathrm{P}$ - and $\mathrm{S}$ onsets are visible for most events in the sequence. The KKAR array - Karatau, Kazakhstan - is at a distance of approximately 9 degrees and displays clear Pn and Sn arrivals for the majority of events. Many of the most poorly constrained solutions in the ISC catalog are single array location estimates using Pn and Sn arrival times at KKAR, together with the estimated backazimuth. The Kyrgyz Seismic Telemetry Network (KNET) is also to the north of the sequence and most stations of this network recorded many events with both Pn and Sn phases. The stations G.HYB, II.ABKT, IC.LSA and IC.WMQ in principle provide good spatial coverage but they, like MKAR, are at far regional distances for which the signals are complicated and emergent and the value these stations have added to relocating large numbers of events is limited. More usefully, at slightly greater distances, are the stations ZAL, KZ.AKTO, IU.CHTO, together with stations of a temporary deployment in Oman (The Dhofar Seismic Experiment II, network code YR) which provide spatial constraints for events above magnitude 4.5. The ${ }_{140}$ YR readings provide useful constraints to the South West.

The highly sensitive stations GARM, DUSH, and SHAA of the Tadjikistan 
network (TJ) came online unfortunately a few weeks after the start of the sequence, but provide useful constraints for some later aftershocks. The most valuable of the untapped resources is the MANAS Profile (network code XP). This line of broadband stations extends several hundred km from the Kazakhstan/Kyrgyzstan border south to the city of Kashgar in North West China. While the azimuthal coverage that the profile offers is limited, the signals are very high frequency and display very clear signal onsets for both Pn and Sn phases. The smallest events for which there is a chance of location are recorded with $\mathrm{P}$ and $\mathrm{S}$ waves by NIL to the South, KKAR to the North West, and by KNET and the most sensitive stations of the MANAS profile to the North East. Simply using many arrivals from this profile in a classical location inversion would likely introduce bias to the solutions since overestimates or underestimates of the traveltimes in directions with good station coverage would outweigh the constraints provided by stations in other directions. Mitigation of this problem could include the calibration of corrections to the traveltimes for these stations using the best located events as reference events. The Bayesloc program essentially performs this calibration and correction implicitly.

\section{Event relocations}

While the existing event bulletins contain many very well constrained events, the vast numbers of additionally available stations which had not contributed to any existing catalogs made a compelling case to apply a new kind of algorithm to build up a regionalized earthquake catalog from scratch. Gibbons et al. (2016) describe a procedure for classifying events in a limited source region using distant stations. Firstly, waveform traces are formed for each station - optimized for detecting seismic arrivals from events in the source region. Secondly, an autoregressive characteristic function is formed for each phase sought, which attains a local maximum close to the signal arrivals. Thirdly, a grid search is performed where each of these characteristic functions are scanned for event 
KKAR, and the MANAS profile stations make all of these waveforms ideal candidates for the autoregressive approach.

Figure 4 shows typical waveform traces optimized for the detection of the indicated phase on the indicated station. This time-window was examined for all stations considered for inclusion in the automatic search for events; if there were not at least 3 clear signals visible in this section, it was deemed unlikely that the station would contribute significantly to the event relocation attempt. The procedure outlined by Gibbons et al. (2016) uses precalculated look-up tables for each phase sought, evaluated over a fixed-depth mesh covering the geographical region displayed in Figure 1. Traveltimes were calculated using the 3-dimensional earth model and raytracing code of Simmons et al. (2015); details are provided in the acknowledgements. The grid search algorithm provides a provisional automatic event catalog and, for events defined by a significant number of both regional and teleseismic phase arrivals, the solutions were augmented with additonal (teleseismic) phases from the REB.

Given that over 1000 event hypotheses had been generated by the automatic procedure, a complete probabilistic relocation of the events identified was attempted in multiple stages - each with an increasing number of events - in order to better assess the robustness of the solutions. In the first stage, an initial set of the best constrained events was examined to determine how well these could provide prior constraints. The set consisted of all events with at least 25 teleseismic $\mathrm{P}$ arrivals, at least 9 regional $\mathrm{Pn}$ phases, and at least 7 regional $\mathrm{Sn}$ phases. For each event, using different subsets of the total number of phases recorded, multiple single-event location calculations were made both using a direct grid search method and the HYPOSAT routine (Schweitzer, 2001). Prior uncertainty constraints for these events were estimated based upon the spread of hypocenter estimates from these initial calculations. However, the uncertainties provided to Bayesloc were increased considerably since non-zero mean and nonGaussian uncertainties in the input parameters are likely to provide additional 200 uncertainty to the hypocenter location estimates (see e.g. Myers et al., 2011).

Two separate runs of Bayesloc were performed for this initial set of the best 
constrained events. The first used only teleseismic P-phases and the second used all of the phases: teleseismic $\mathrm{P}$, regional $\mathrm{P}$, and regional $\mathrm{S}$. The outputs from the teleseismic-only and all-phase runs of Bayesloc were compared in order to verify that the regional phases (given the unfavourable spatial distribution of stations) were not introducing an unacceptable bias into the solutions.

Having confirmed that the location estimates for the best constrained events were not affected adversely by combining the teleseismic and the regional phase arrival times, subsequent runs of Bayesloc were performed with new events with fewer defining phases being added at each stage. The ratio of teleseismic to regional phases decreases as the number of defining phases goes down until, for the lowest magnitude events, we have only regional phases defining the event. Figure 5 displays the distribution of mean hypocenter estimates from Bayesloc at the stage where there are 1308 events.

The two clusters of seismicity for the existing bulletins (Figure1) are far more sharply defined following the relocation procedure. Whereas the event density in the REB and ISC bulletins simply decreases towards the South West, the relocated clusters are limited by a surprisingly sharp North West to South East trending boundary. For the southern cluster, this limiting line is approximately parallel to, and a few km South West of, the surface rupture of the BalaklotBagh Thrust. The October 8, 2005, mainshock is at the northern tip of this southern cluster and almost all events in this cluster are bounded to the north by the Main Boundary Thrust. The seismicity in the northern cluster fills the so-called Indus-Kohistan Seismic Zone (e.g. Jouanne et al. 2011), North West of the Balaklot-Bagh Thrust and bounded between the Main Central Thrust and the Main Mantle Thrust to the North.

The diffuse seismicity in Figure 1 to the North and East of the two main clusters is resolved into two smaller scale structures in Figure 5 . Most of the earthquakes in these two clusters are relatively small in magnitude (4 or less) and are typically recorded only by the regional stations. The enormous scatter in the ISC catalog is simply a result of poorly constrained solutions; the readings from NIL and stations of the MANAS profile apply significant constraints to 
these event locations. One of these formations extends to the North East, short of the Main Mantle Thrust. The other formation is a band of seismicity starting at the northernmost turning point of the Main Central Thrust and extending 30 or so km East South East into the Kashmir Basin.

Focal mechanisms are provided by http://www.globalcmt.org/CMTsearch.html (Dziewonski et al., 1981; Ekström et al., 2012) for 37 of the largest events in this sequence, of which the vast majority are in the largest North West cluster of aftershock activity. Figure 6 a) displays the Centroid Moment Tensor solutions obtained from globalcmt.org both with the published location and the relocation. It is clear that the majority of the events are thrust earthquakes with a strike angle similar to the North West to South East trend of the aftershock clusters (e.g. Avouac et al. 2006). The relocated epicenters (Figure 6 ${ }_{245}$ b) occupy a far more limited geographical region than the originally published solutions. As importantly, there appears to be great consistency in how the source parameters change over this region. The strike angles for the events in the North West of this cluster appear significantly lower (280-300 degrees) than for events in the South of the cluster (strike angle 325-350 degrees). There are two events with strike-slip characteristics which are relocated into far closer proximity of each other in the East of the cluster. Since the CMT solutions did not affect the relocation in any way, the observed spatial similarity of the source mechanisms provides, independently, additional confidence in the new epicenter estimates. Similarly, the relocations suggest that the indicated focal 255 mechanisms are relatively characteristic of any given region of the aftershock zone and that the source parameters are varying spatially with a length scale of the order 10-15 km. A systematic investigation of the focal mechanisms for smaller events would require far more seismic data from closer distances which, to the best of our knowledge, does not exist. 


\section{Conclusions}

The spatial distribution of aftershocks to the October 8, 2005, M=7.6 Kashmir earthquake can provide useful information about the tectonics of the region. However, existing catalogs of earthquakes in this sequence are of relatively poor quality. We seek to rectify this by examining seismic data which has to date not been exploited, by employing optimized signal processing algorithms to pick and associate phase arrivals autonomously, by employing more recent and more realistic seismic velocity models, and lastly by utilizing a Bayesian multiple event location algorithm. The location estimates for events have been improved significantly in particular by a careful exploitation of waveforms recorded at regional distances.

The relocated aftershocks are split into four main zones. The vast majority of events form two large clusters to the North West and South East of the main event. Both clusters are limited to the South West by a NWSE trending boundary which lies close to the surface rupture of the BalaklotBagh Thrust for the southern cluster. The remaining seismicity is of relatively low magnitude and is arranged in two clusters which radiate North East and East South East from the most northerly turning point of the Main Central Thrust. We have obtained Centroid Moment Tensor solutions from http://www.globalcmt.org/CMTsearch.html and the relocations indicate that there is significant clustering of events with similar focal mechanisms. This provides both confidence in the relocated epicenters and in the degree to which an estimated focal mechanism is representative of a given region of the aftershock zone. Obtaining focal mechanisms for smaller events would be of exceptional value, in particular for the smaller scale structures in the aftershock distribution. However, given the smaller magnitude of events in these regions, obtaining accurate focal mechanism estimates would require observations with a far better spatial coverage than is available to us.

We have included as supplementary material all of the files necessary to run a Bayesloc relocation for this particular sequence. This will allow an open 
and rigorous evaluation of the robustness of the solutions presented and may motivate a refinement of the solutions using seismic data not available to us. Only seismicity between October 8, 2005, and December 31, 2005, was covered in the present study. The event density towards the end of this time-interval was fairly low and it was deemed that extending the search period would have diminishing returns. Again, combining the data provided with readings for events from different time-intervals, possibly on stations not available at the time of the 2005 sequence, may result in additional constraints on the distributions of seismicity derived.

\section{Acknowledgements}

This work was partially supported by the Air Force Research Laboratory under Contract number FA9453-11-C-0230.

All maps in this paper are created using GMT software (Wessel and Smith, 1995).

We are grateful to Roger Bilham for discussions about seismicity in the Indo-Asian Collision Zone and for encouragement to publish these aftershock relocations.

The bulletin of the International Seismological Center (ISC) is available from http://www.isc.ac.uk/ (last referenced June 2017).

Waveform data for IMS seismic stations was obtained from the International Data Center for the Comprehensive Nuclear-Test-Ban Treaty Organization in Vienna.

Waveforms from all arrays in the Kazakhstan network were provided courtesy of the Kazakhstan National Data Center and we are grateful to Terri Hauk for preparation of these data.

Additional waveforms were obtained via the Incorporated Research Institutes for Seismology Data Management Center at

http://ds.iris.edu/SeismiQuery/by_station.html 
(last accessed June 2017). We have utilized data from the networks AK, KN, XP, KZ, RO, IC, II, IU, YR, AU, CN, AT, G, GT, MY and TJ and we gratefully acknowledge the operators of these networks for making the data available.

The LLNL-G3D global 3-dimensional P-wave velocity model and ray-tracing software is available from

https://missions.llnl.gov/nonproliferation/nuclear-explosion-monitoring/global-3d-seismic-tomograpl

$325 \quad$ (last accessed June 2017).

The Bayesloc multiple event location software and documentation is available from

https://www-gs.llnl.gov/about/nuclear-threat-reduction/nuclear-explosion-monitoring/bayesloc

$330 \quad$ (last accessed June 2017).

Centroid Moment Tensor solutions were obtained from http://www.globalcmt.org/CMTsearch.html

(last accessed June 2017).

\section{References}

Ali, Z., Qaisar, M., Mahmood, T., Shah, M.A., Iqbal, T., Serva, L., Michetti, A.M., Burton, P.W., 2009. The Muzaffarabad, Pakistan, earthquake of 8 October 2005: surface faulting, environmental effects and macroseismic intensity. Geological Society, London, Special Publications 316, 155-172. doi:10.1144/sp316.9.

Avouac, J., Ayoub, F., Leprince, S., Konca, O., Helmberger, D., 2006. The 2005, Mw 7.6 Kashmir earthquake: Sub-pixel correlation of ASTER images and seismic waveforms analysis. Earth and Planetary Science Letters 249, 514-528. doi: $10.1016 /$ j.epsl.2006.06.025

Ballard, S., Hipp, J.R., Begnaud, M.L., Young, C.J., Encarnacao, A.V., Chael, 345 E.P., Phillips, W.S., 2016. SALSA3D: A Tomographic Model of Compres- 
sional Wave Slowness in the Earth's Mantle for Improved Travel-Time Prediction and Travel-Time Prediction Uncertainty. Bulletin of the Seismological Society of America doi $10.1785 / 0120150271$.

Bendick, R., Bilham, R., Khan, M.A., Khan, S.F., 2006. Slip on an active wedge thrust from geodetic observations of the 8 October 2005 Kashmir earthquake. Geology 35, 267-270. doi $10.1130 / g 23158$ a. 1.

Bilham, R., 2004. Earthquakes in India and the Himalaya: tectonics, Geodesy and history. Annals of Geophysics 47, 839-858.

Bungum, H., Lindholm, C.D., Mahajan, A.K., 2017. Earthquake recurrence in NW and central Himalaya. Journal of Asian Earth Sciences 138, 25-37. doi $10.1016 / j \cdot$ jseaes.2017.01.034.

Dodge, D.A., Harris, D.B., 2016. Large-Scale Test of Dynamic Correlation Processors: Implications for Correlation-Based Seismic Pipelines. Bulletin of the Seismological Society of America 106, 435-452. doi:10.1785/0120150254

360 Douglas, A., 1967. Joint Epicentre Determination. Nature 215, 47-48. doi 10. $1038 / 215047 \mathrm{a} 0$

Dziewonski, A.M., Chou, T.A., Woodhouse, J.H., 1981. Determination of earthquake source parameters from waveform data for studies of global and regional seismicity. J. Geophys. Res. 86, 2825-2852. doi 10.1029/jb086ib04p02825. 2004-2010: Centroid-moment tensors for 13,017 earthquakes. Physics of the n Earth and Planetary Interiors 200-201, 1-9. doi 10.1016/j.pepi.2012.04. 002 .

Gavillot, Y., Meigs, A., Yule, D., Heermance, R., Rittenour, T., Madugo, C., 370 Malik, M., 2016. Shortening rate and Holocene surface rupture on the Riasi fault system in the Kashmir Himalaya: Active thrusting within the Northwest Himalayan orogenic wedge. Geological Society of America Bulletin , B31281.1+doi $10.1130 / \mathrm{b} 31281.1$. 
Gibbons, S.J., Kværna, T., Harris, D.B., Dodge, D.A., 2016. Iterative Strategies for Aftershock Classification in Automatic Seismic Processing Pipelines. Seismological Research Letters 87, 919-929. doi:10.1785/0220160047.

Gibbons, S.J., Ringdal, F., Kværna, T., 2012. Ratio-to-moving-average seismograms: a strategy for improving correlation detector performance. Geophysical Journal International 190, 511-521. doi $10.1111 / j .1365-246 x .2012$. 05492.x.

Harris, D.B., Dodge, D.A., 2011. An Autonomous System for Grouping Events in a Developing Aftershock Sequence. Bulletin of the Seismological Society of America 101, 763-774. doi:10.1785/0120100103.

Jouanne, F., Awan, A., Madji, A., Pêcher, A., Latif, M., Kausar, A., Mugnier, J.L., Khan, I., Khan, N.A., 2011. Postseismic deformation in Pakistan after the 8 October 2005 earthquake: Evidence of afterslip along a flat north of

a the Balakot-Bagh thrust. J. Geophys. Res. 116, B07401+. doi 10.1029/ $2010 j b 007903$

Junek, W.N., Kværna, T., Pirli, M., Schweitzer, J., Harris, D.B., Dodge, D.A., Woods, M.T., 2015. Inferring Aftershock Sequence Properties and Tectonic Structure Using Empirical Signal Detectors. Pure and Applied Geophysics 172, 359-373. doi:10.1007/s00024-014-0938-0

Kaneda, H., Nakata, T., Tsutsumi, H., Kondo, H., Sugito, N., Awata, Y., Akhtar, S.S., Majid, A., Khattak, W., Awan, A.A., Yeats, R.S., Hussain, A., Ashraf, M., Wesnousky, S.G., Kausar, A.B., 2008. Surface Rupture of the 2005 Kashmir, Pakistan, Earthquake and Its Active Tectonic Implications.

a Bulletin of the Seismological Society of America 98, 521-557. doi 10.1785/ 0120070073

Kennett, B.L.N., Engdahl, E.R., Buland, R., 1995. Constraints on seismic 400 velocities in the Earth from traveltimes. Geophysical Journal International 122, 108-124. doi $10.1111 / \mathrm{j} .1365-246 \mathrm{x} .1995 . \mathrm{tb03540.x}$. 
Kværna, T., Ringdal, F., 2013. Detection Capability of the Seismic Network of the International Monitoring System for the Comprehensive Nuclear-TestBan Treaty. Bulletin of the Seismological Society of America 103, 759-772. doi:10.1785/0120120248.

Lieshout, M.N.M., Stein, A., 2012. Earthquake Modelling at the Country Level Using Aggregated Spatio-Temporal Point Processes. Mathematical Geosciences 44, 309-326. doi $10.1007 /$ s11004-011-9380-3.

Mandal, P., Chadha, R.K., Kumar, N., Raju, I.P., Satyamurty, C., 2007. Source Parameters of the Deadly Mw 7.6 Kashmir Earthquake of 8 Oc口 tober, 2005. Pure and Applied Geophysics 164, 1963-1983. doi 10.1007/ s00024-007-0258-8.

MonaLisa, 2009. Recent seismic activity in the NW Himalayan Fold and Thrust Belt, Pakistan: focal mechanism solution and its tectonic implications. Geological Society, London, Special Publications 316, 259-267. doi: $10.1144 / \mathrm{sp} 316.16$

Murphy, J.R., Rodi, W., Johnson, M., Sultanov, D.D., Bennett, T.J., Toksöz, M.N., Ovtchinnikov, V., Barker, B.W., Reiter, D.T., Rosca, A.C., Shchukin, Y., 2005. Calibration of International Monitoring System (IMS) Stations in Central and Eastern Asia for Improved Seismic Event Location. Bulletin of the Seismological Society of America 95, 1535-1560. doi:10.1785/0120040087.

Myers, S.C., Begnaud, M.L., Ballard, S., Pasyanos, M.E., Phillips, W.S., Ramirez, A.L., Antolik, M.S., Hutchenson, K.D., Dwyer, J.J., Rowe, C.A., Wagner, G.S., 2010. A Crust and Upper-Mantle Model of Eurasia and North ${ }_{425}$ Africa for Pn Travel-Time Calculation. Bulletin of the Seismological Society of America 100, 640-656. doi:10.1785/0120090198.

Myers, S.C., Johannesson, G., Hanley, W., 2007. A Bayesian hierarchical method for multiple-event seismic location. Geophysical Journal International 171, 1049-1063. doi 10.1111/j.1365-246x.2007.03555.x. 
Myers, S.C., Johannesson, G., Hanley, W., 2009. Incorporation of probabilistic seismic phase labels into a Bayesian multiple-event seismic locator. Geophysical Journal International 177, 193-204. doi:10.1111/j.1365-246x.2008. 04070.x.

Myers, S.C., Johannesson, G., Simmons, N.A., 2011. Global-scale P wave tomography optimized for prediction of teleseismic and regional travel times for Middle East events: 1. Data set development. Journal of Geophysical Research 116, B04304+. doi 10.1029/2010jb007967.

Myers, S.C., Simmons, N.A., Johannesson, G., Matzel, E., 2015. Improved Regional and Teleseismic P-Wave Travel-Time Prediction and Event Location Using a Global 3D Velocity Model. Bulletin of the Seismological Society of America 105, 1642-1660. doi:10.1785/0120140272.

Parsons, T., Ogata, Y., Zhuang, J., Geist, E.L., 2012. Evaluation of static stress change forecasting with prospective and blind tests. Geophysical Journal International 188, 1425-1440. doi $10.1111 / \mathrm{j} .1365-246 \mathrm{x} .2011 .05343 . \mathrm{x}$.

445 Parsons, T., Yeats, R.S., Yagi, Y., Hussain, A., 2006. Static stress change from the 8 October, 2005 M = 7.6 Kashmir earthquake. Geophysical Research Letters 33, L06304+. doi $10.1029 / 2005$ g1025429

Pathier, E., Fielding, E.J., Wright, T.J., Walker, R., Parsons, B.E., Hensley, S., 2006. Displacement field and slip distribution of the 2005 Kashmir earthquake

450 from SAR imagery. Geophysical Research Letters 33, L20310+. URL: http: //dx.doi.org/10.1029/2006gl027193, doi:10.1029/2006gl027193

Schweitzer, J., 2001. HYPOSAT - An Enhanced Routine to Locate Seis-

\ mic Events. Pure and Applied Geophysics 158, 277-289. doi 10.1007/ pl00001160.

455 Simmons, N.A., Myers, S.C., Johannesson, G., Matzel, E., Grand, S.P., 2015. Evidence for long-lived subduction of an ancient tectonic plate beneath the 
¿ southern Indian Ocean. Geophys. Res. Lett. 42, 2015GL066237+. doi 10 . $1002 / 2015 g 1066237$.

Slinkard, M.E., Carr, D.B., Young, C.J., 2013. Applying Waveform Correlation to Three Aftershock Sequences. Bulletin of the Seismological Society of America 103, 675-693. doi:10.1785/0120120058.

Tahir, M., Grasso, J.R., 2014. Aftershock Patterns of Ms¿7 Earthquakes in the India-Asia Collision Belt: Anomalous Results from the Muzaffarabad Earthquake Sequence, Kashmir, 2005. Bulletin of the Seismological Society of America 104, 1-23. doi:10.1785/0120120158.

Türkyilmaz, K., Lieshout, M.N.M., Stein, A., 2013. Comparing the Hawkes and Trigger Process Models for Aftershock Sequences Following the 2005

घ Kashmir Earthquake. Mathematical Geosciences 45, 149-164. doi 10.1007/ s11004-012-9438-x.

470 Waldhauser, F., Ellsworth, W.L., 2000. A Double-Difference Earthquake Location Algorithm: Method and Application to the Northern Hayward Fault, California. Bulletin of the Seismological Society of America 90, 1353-1368. doi:10.1785/0120000006.

Wessel, P., Smith, W.H.F., 1995. New version of the Generic Mapping Tools. EOS Trans. Am. Geophys. Union 76, 329.

Yan, Y., Pinel, V., Trouvé, E., Pathier, E., Perrin, J., Bascou, P., Jouanne, F., 2013. Coseismic displacement field and slip distribution of the 2005 Kashmir earthquake from SAR amplitude image correlation and differential interferometry. Geophysical Journal International 193, 29-46. doi 10.1093/gji/ggs102 


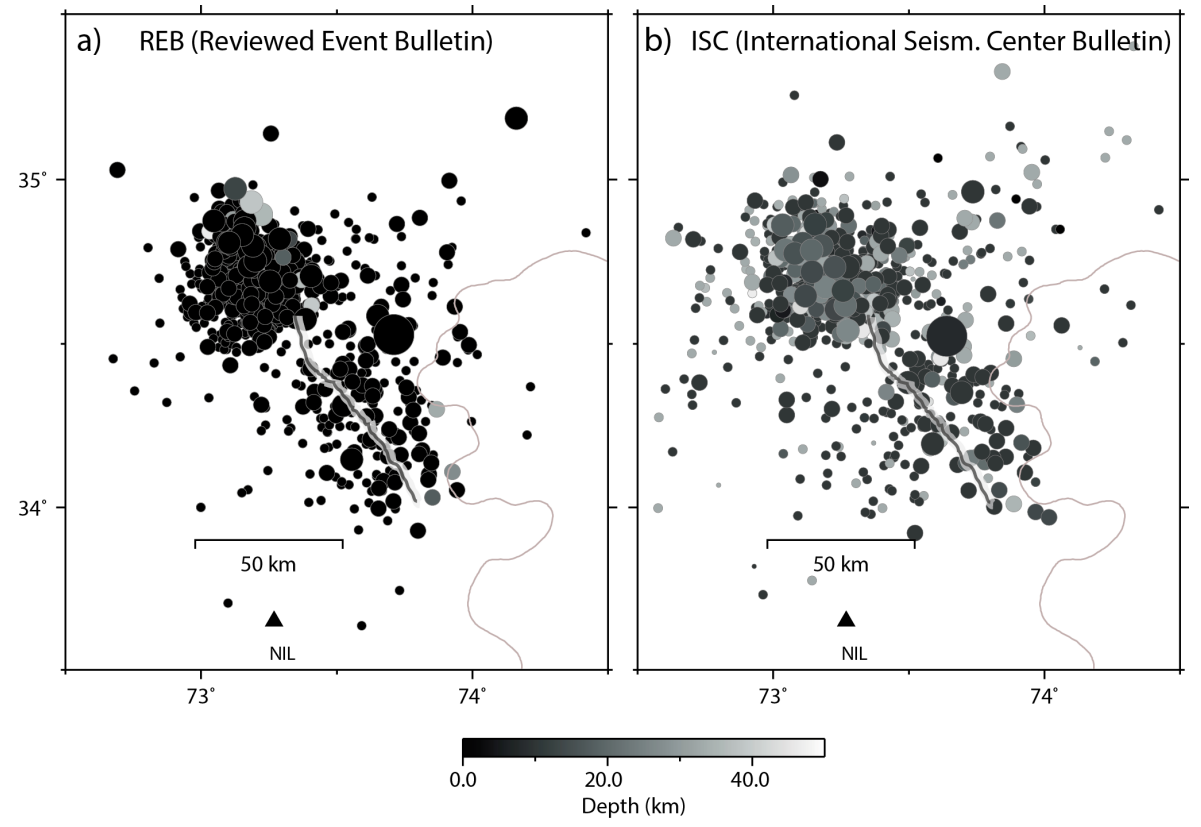

Figure 1: Event location estimates (a) from the Reviewed Event Bulletin (REB) of the International Data Center (IDC) of the Comprehensive Nuclear-Test-Ban Treaty Organization (CTBTO), and (b) from the International Seismological Center (www.isc.ac.uk). The location of the closest open station to recorded the sequence (NIL: Nilore, Pakistan) is displayed, although readings from this station did not contribute to either catalog. The NW-SE trending line is the trace of the Balaklot-Bagh thrust fault surface rupture traced from Pathier et al. (2006). 


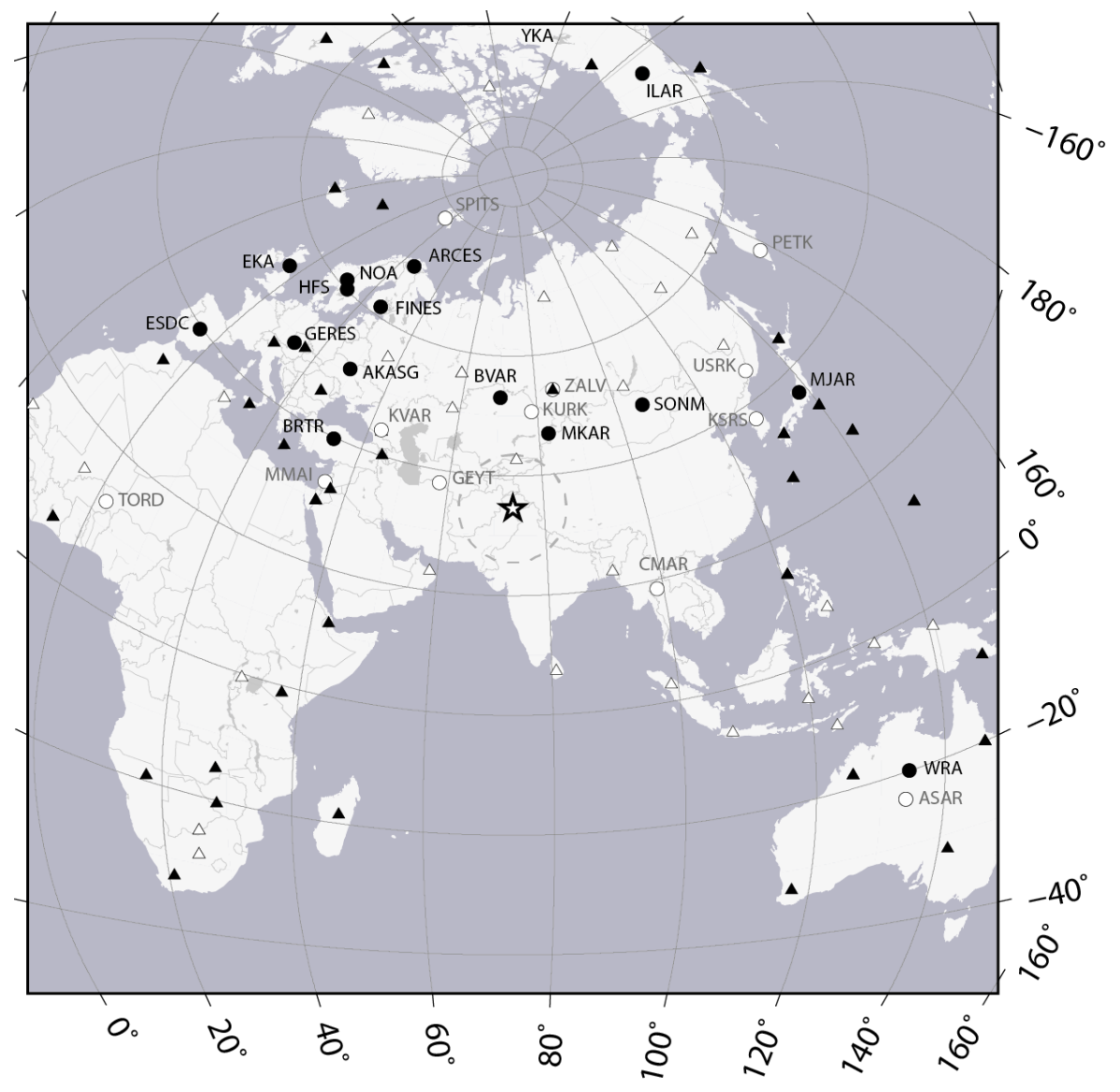

Figure 2: Stations of the International Monitoring System (IMS) in relation to the Kashmir earthquakes (star). Black/white symbols indicate stations operational/not operational at the time of the earthquake. Arrays and 3-component stations are marked by circles and triangles respectively. 


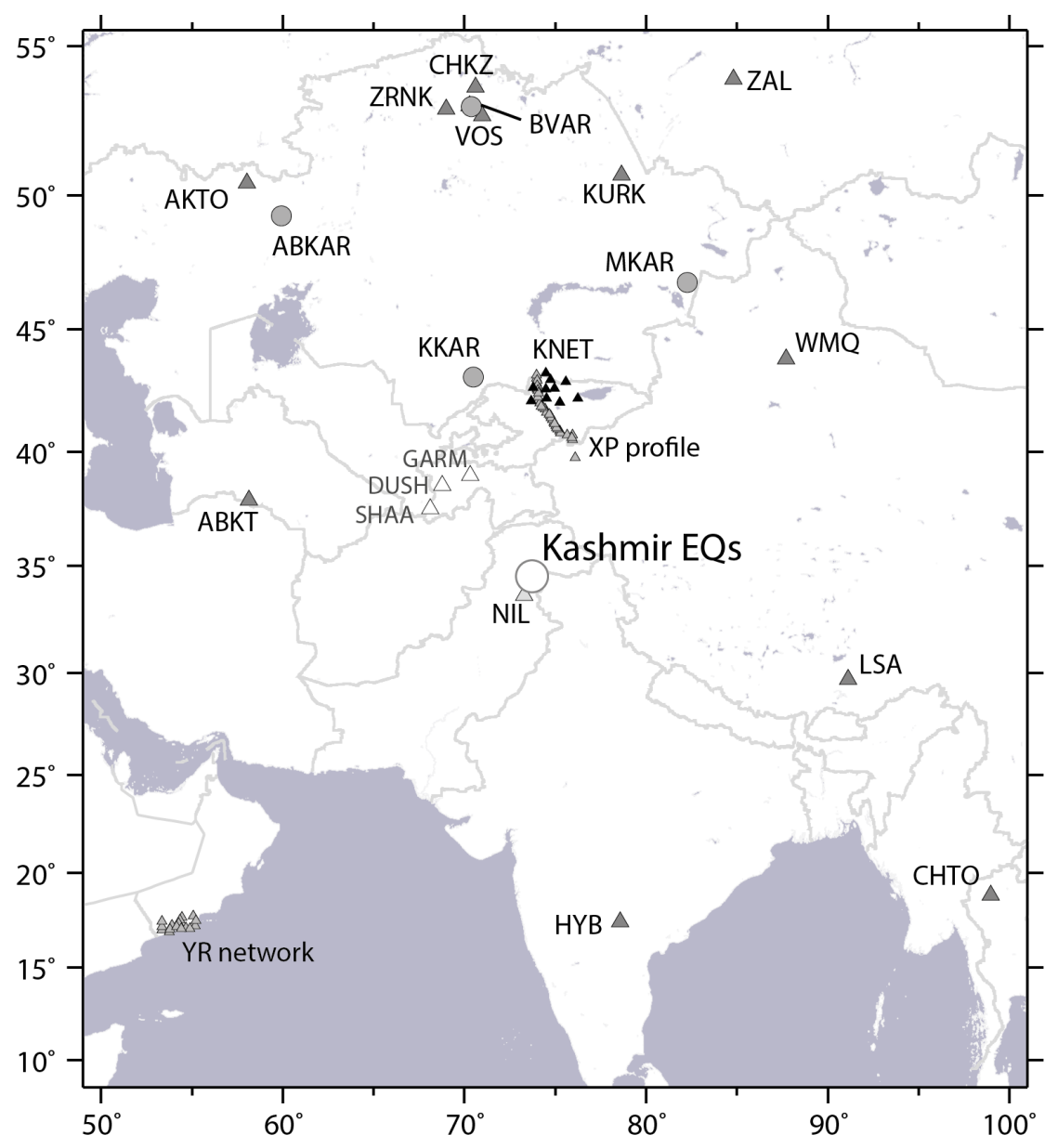

Figure 3: Stations with open access which recorded the Kashmir sequence. The TJ network stations GARM, DUSH, and SHAA did not come online until several weeks after the mainshock. Arrays and 3-component stations are marked by circles and triangles respectively. 


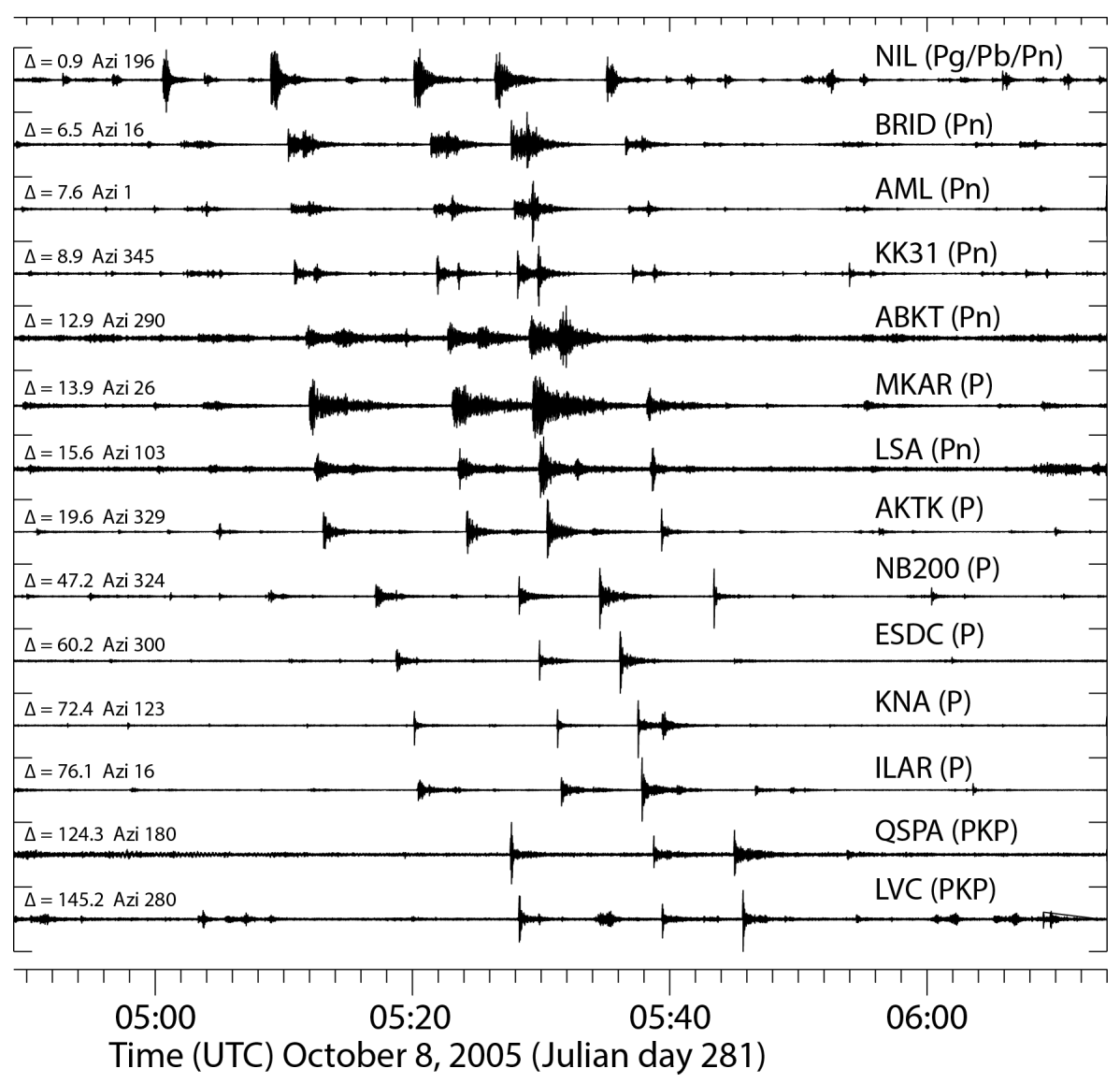

Figure 4: Waveform traces from a selected set of stations optimized for the phases labelled for a 90 minute interval about one hour after the mainshock. Optimized means that bandpass filtering in a frequency band for which the arrival is anticipated to have an optimal signal-tonoise-ratio (SNR). For array stations, a beam has been performed with steering parameters aimed at maximizing the SNR. 


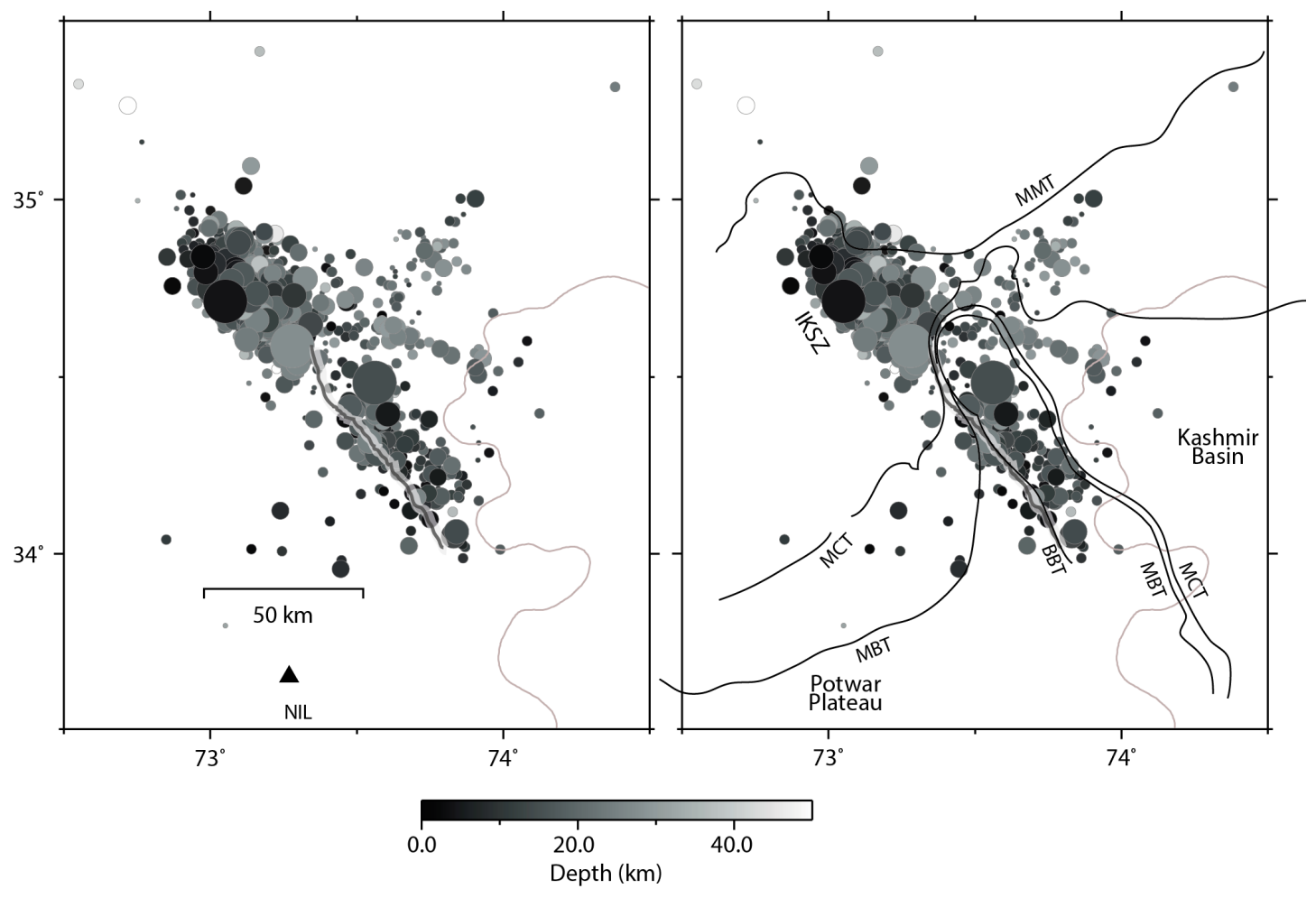

Figure 5: Mean hypocenters output from Bayesloc. At left we display only the location estimates together with the surface rupture only and at right we display the locations together with features marked by Jouanne et al. (2011) and Gavillot et al. (2016). BBT is BalaklotBagh thrust, MBT is Main Boundary Thrust, MCT is Main Central Thrust, MMT is Main Mantle Thrust, and IKSZ is Indus-Kohistan Seismic Zone. 

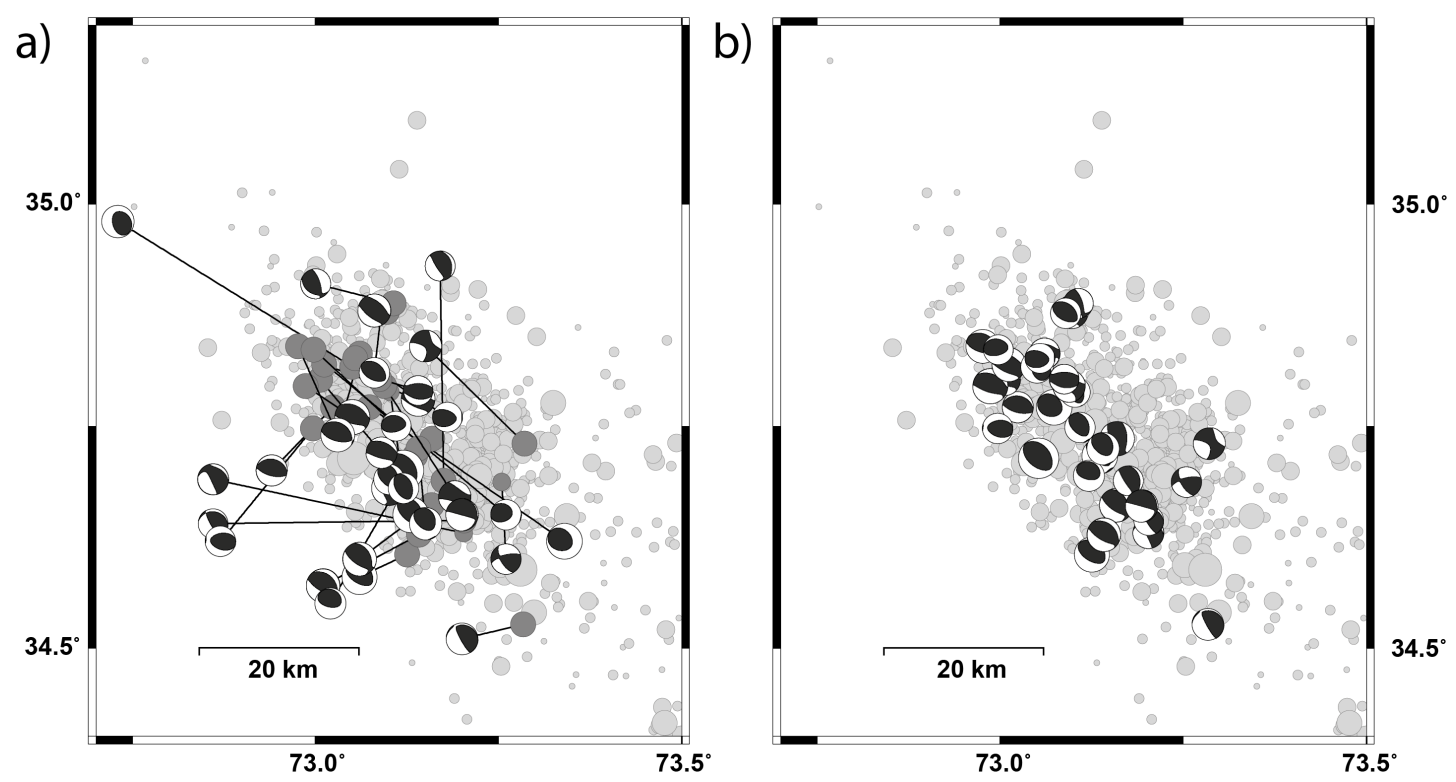

Figure 6: Epicenters of relocated events from the North West aftershock cluster together with focal mechanisms for all events available from from http://www.globalcmt.org/CMTsearch.html (these are typically events above magnitude 5). a) Displays the symbols at the locations provided by globalcmt.org with lines connecting each symbol to the relocated epicenter and b) displays the symbols at the relocated epicenters. Note that events even of this size have been relocated by in excess of 30 $\mathrm{km}$. 